\title{
ANÁLISE DAS IMPLICATURAS E A VIOLAÇÃO DAS MÁXIMAS CONVERSACIONAIS NA SÉRIE THE BIG BANG THEORY
}

\begin{abstract}
Jéssica Tayrine Gomes de Melo Bezerra ${ }^{1}$
RESUMO: O presente trabalho tem o objetivo de analisar recortes de diálogos realizados na série The Big Bang Theory sob a perspectiva da pragmática conversacional (GRICE, 1975). Mais especificamente, é analisado como o humor verbal da série é ocasionado pela Violação das Máximas Conversacionais, pelas implicaturas e pela relação dos interlocutores na mudança do modo bona-fide para o modo não bona-fide de comunicação (RASKIN, 1985). Verifica-se que a intenção das violações das máximas nos recortes analisados é o humor e que a não destacabilidade das implicaturas permite a percepção do humor mesmo na tradução literal do corpus analisado, corroborando com o caráter universal do humor.
\end{abstract}

PALAVRAS-CHAVE: Pragmática Conversacional. Máximas conversacionais. Implicaturas. Humor.

\section{Introdução}

A Pragmática é a subárea da Linguística que investiga o funcionamento da linguagem através das atribuições de intenção emitidas pelas sentenças proferidas. Dessa forma, com base nessa perspectiva, a linguagem deve ser estudada e entendida através do uso em situações concretas de fala: são observados os significados enunciados pelos falantes e como os enunciados são interpretados pelos ouvintes em uma determinada conversa.

Um dos primeiros estudos que iniciou o debate pragmático formal partiu de Paul Grice, um filósofo da linguagem. Grice (1975) indica que o fator central da comunicação é o reconhecimento por parte do interlocutor, dos conhecimentos, das intenções e expectativas que um falante transmite ao dizer algo: o falante diz algo que deve ser interpretado pelo seu significado literal e espera que o ouvinte interprete da maneira adequada às necessidades da conversa. Dessa forma, os participantes cooperam tacitamente, inicialmente, um com os outros, seguindo regras que regem a conversação. Com isso, o autor propõe o Princípio da Cooperação e a existência de máximas e submáximas que contribuem com a negociação do sentido conversacional que fazem com que uma conversa seja bem-sucedida.

Por vezes, o falante não segue as Máximas Conversacionais e, mesmo assim, espera que o ouvinte entenda o sentido implícito do que está sendo dito.

\footnotetext{
1 Mestre em Linguística pela Universidade Federal da Paraíba - UFPB. E-mail: jtayrine@gmail.com.
} 
Quando isso ocorre, é dito que houve a Violação das Máximas Conversacionais e o falante espera que o ouvinte compreenda o enunciado a partir da intenção implícita, das implicaturas, e não do sentido literal.

No processo de construção do humor em comédias de situação, situation comedy ou a abreviação sitcom, o humor é construído a partir de caricaturas e exageros sobre questões cotidianas de uma determinada comunidade. Assim, conversas que ocorrem comumente no cotidiano real das pessoas podem ser vistas em uma sitcom, o que pode indicar a presença das violações das máximas conversacionais nos diálogos dos personagens. Atualmente, o exemplo mais famoso de sitcom é a série The Big Bang Theory, cuja estreia ocorreu em 2007, na televisão norte-americana, e que aborda o cotidiano de quatro amigos tipicamente nerds (ou geeks) (GALVÃO, 2009).

Neste artigo, o objetivo é analisar diálogos realizados na sitcom The Big Bang Theory através dos aspectos conversacionais da produção do humor ocasionado pela quebra das máximas conversacionais. $\mathrm{Na}$ sitcom, a linguagem ocorre em um contexto situacional e há negociação de sentido entre os interlocutores fictícios e reais, o que permite uma análise por parte da Pragmática Conversacional (GRICE, 1975), "pois todo humor que é gerado a partir da quebra de princípios conversacionais pode ser explicado por meio dos princípios teóricos da análise da conversação" (TRAVAGLIA, 1990, p. 63). Ou seja, nos diálogos realizados nesse tipo de série de humor há conteúdos implícitos que podem ser entendidos tanto pelos personagens quanto pelos espectadores através da atuação do Princípio da Cooperação e da compreensão das implicaturas e, principalmente, da quebra de expectativas ocasionada pela Violação das Máximas Conversacionais.

O humor pode ser identificado através da transição do modo bona-fide para o modo não bona-fide de comunicação (RASKIN, 1985), percebida pelos falantes fictícios e reais. Além disso, para compreender a identificação que os espectadores possuem com a série, é preciso levar em consideração as situações conversacionais nas quais os personagens estão inseridos. 


\section{$1 \quad$ Pragmática Conversacional}

A Pragmática Conversacional teve início com o trabalho seminal "Lógica e Conversação", do filósofo H. P. Grice, publicado em 1975. No contexto da época, o autor buscou superar as propostas linguísticas feitas pela abordagem formal e pela abordagem conversacional radical, vistas como antagônicas. Assim, surge a teoria da conversação com uma proposta de relacionar as inferências pragmáticas à lógica ou gramática: o significado do falante e o significado da sentença, respectivamente:

Grice qualifica de erro supor que há uma divergência entre essas posições - a dos formalistas e a dos conversacionalistas. De fato, ele afirma que essas duas posições são complementares, e que os conflitos, contradições e divergências entre elas são apenas aparentes. Quando conversamos dizemos ao mesmo tempo que 'implicamos' (OLIVEIRA e BASSO, 2014, p. 19).

Assim, a significação total de uma elocução depende dos fenômenos dizer e implicar: o significado literal de uma sentença e as informações implícitas dadas por um falante. Em suma, ao realiza-se uma proposição (dizer), a informação é dita semanticamente. Quando uma implicatura é realizada, a informação é inferida pelo ouvinte através do que é dito, da significação de um proferimento, juntamente com o contexto situacional de fala.

\subsection{Princípio da Cooperação e as Máximas Conversacionais}

De acordo com Grice (1975), toda conversação é regida pelo Princípio da Cooperação, ou seja, em uma conversa, as pessoas buscam entender e se fazer entendidas através de um pacto implícito que opera da seguinte maneira: "faça sua contribuição conversacional tal como é requerida, no momento em que ocorre, pelo propósito ou direção do intercâmbio conversacional em que você está engajado" (GRICE, 1975, p. 45). Com isso, o autor reforça a ideia de que a 
linguagem do cotidiano tem significados diferentes dos significados trabalhados pela lógica formal. Porém:

Grice não tinha a intenção de acusar os falantes comuns de ser desleixados ou ilógicos. Pelo contrário, ele propôs que o uso da língua na conversação possui uma racionalidade específica, enraizada na necessidade de os parceiros da conversação cooperarem entre si para transmitir sua mensagem (PINKER, 2008, p. 429).

A partir do Princípio da Cooperação, o autor descreve quatro categorias, ou máximas, que contribuem com a eficiência de uma prática conversacional (Grice, 1975, p. 45-46):

- $\quad$ Máxima da Quantidade

1. Faça com que sua contribuição seja tão informativa quanto requerido (para o propósito corrente da conversação).

2. Não faça sua contribuição mais informativa do que é requerido.

- $\quad$ Máxima da Qualidade

1. Trate de fazer uma contribuição que seja verdadeira

2. Não diga o que você acredita ser falso.

3. Não diga senão aquilo para que você possa fornecer evidência adequada.

- Máxima da Relação

1. Seja relevante.

- Máxima de Modo

1. Evite obscuridade de expressão.

2. Evite ambiguidades. 
3. Seja breve (evite prolixidade desnecessária).

4. Seja ordenado.

As máximas e as submáximas foram propostas para indicar uma conversação bem-sucedida, que ocorre de maneira feliz e que segue o Princípio da Cooperação. A não observância dessas categorias, não propositalmente, pode principiar mal-entendidos. Quando intencionais, surgem os implícitos pragmáticos: as Implicaturas Conversacionais.

\subsection{Implicaturas Conversacionais e Convencionais}

Certos enunciados significam mais do que a expressão linguística, por si só, apresenta. O significado de um enunciado depende da expressão linguística, do contexto ou dos conhecimentos prévios dos falantes. A partir disso, Grice (1975) propõe a noção de Implicatura Conversacional, apresentadas como inferências que são extraídas dos enunciados, cuja função é fazer com que o objeto ou propósito de um enunciado seja percebido.

As implicaturas surgem da exploração do Princípio Cooperativo. Quando o falante não segue à risca o Princípio da Cooperação, o ouvinte precisa analisar o enunciado e interpretá-lo para que atenda os propósitos conversacionais do momento: assim, o ouvinte percebe que o princípio foi violado aparentemente e faz uma interpretação que vai além do significado da sentença, a implicatura.

Grice expõe a diferença entre Implicatura convencional e Implicatura conversacional. Quando alguém diz algo como "Eu tenho um gato, mas ele é muito simpático", através da união das duas sentenças, por meio da conjunção "mas", pode-se perceber a implicatura: os gatos não são criaturas simpáticas ou os gatos são reservados. Assim, essa significação partiu do significado do item linguístico na relação entre os dois enunciados, por isso é uma Implicatura Convencional (parte do sentido literal das palavras e não precisam necessariamente ocorrer em uma conversação).

Já as Implicaturas Conversacionais estão ligadas a certos traços gerais do discurso. Por exemplo, na sentença "Eles casaram, ninguém apareceu para atrapalhar a cerimônia", há uma implicatura de que alguém relacionado aos 
noivos poderia ter aparecido para atrapalhar o casamento. Essa interpretação parte de conhecimentos prévios que vão além da expressão linguística: quando duas pessoas decidem casar, não deveria existir uma terceira pessoa que pudesse atrapalhar tal desejo ou se existir alguém a mais em uma relação amorosa a dois, um casamento poderia ser atrapalhado e não ocorrer. A implicatura é não convencional, portanto, é considerada conversacional.

Grice também distingue dois tipos de Implicaturas Conversacionais: Implicaturas Conversacionais particularizadas e Implicaturas Conversacionais Generalizadas. As Implicaturas Particularizadas são as que dependem fortemente dos conhecimentos dos interlocutores e de um contexto em particular para serem interpretadas. As Implicaturas Conversacionais Generalizadas podem ser confundidas com Implicaturas Convencionais, pois, quando não existe uma circunstância ou contexto de uso, a interpretação de um enunciado depende de algum tipo de expressão linguística ou do contexto gramatical (embora, não haja um item lexical específico).

Grice focaliza a análise nas Implicaturas Conversacionais Particularizadas. Tais implicaturas possuem quatro características essenciais²:

a) Canceláveis: "são raciocínios abdutivos que funcionam normalmente, mas não sempre" (OLIVEIRA, BASSO, 2014, p. 41).

b) Não destacáveis ou não separáveis: as implicaturas não dependem da estrutura linguística para ocorrer, e sim do conteúdo semântico do que é dito: "em outros termos, a implicatura é destacável da expressão linguística" (OLIVEIRA; BASSO, 2014, p. 43).

c) Calculáveis: é possível identificar que um ouvinte faz inferências para seguir uma conversação cooperativa, a partir do significado literal ou do sentido de uma enunciação, e do Princípio da Cooperação e uso das máximas (LEVINSON, 2007).

d) Não convencionais: não possuem o sentido convencional veiculado pelas estruturas linguísticas (LEVINSON, 2007).

As implicaturas conversacionais são propositais: sempre há intenção do falante violar uma ou mais máximas (respeitando o Princípio da Cooperação) para 2 Dentre as características expostas nesse momento, focalizamos na análise dos dados duas
características: não destacáveis e não convencionais. 
que seja dito ao ouvinte algo a mais que a estrutura linguística possa indicar, para que as implicaturas sejam ativadas. Grice (1975, p. 45) afirma que, quando o falante deixa de cumprir "espalhafatosamente" uma máxima, há, caracteristicamente, a formação de uma implicatura conversacional ${ }^{3}$.

\title{
1.3 Violação das Máximas Conversacionais
}

No processo conversacional, algumas vezes, é preciso violar algumas máximas conversacionais para ocasionar algum efeito de sentido no interlocutor:

\begin{abstract}
Quando o locutor parece não seguir as máximas conversacionais, mas ainda assim espera que o interlocutor infira o sentido implícito, dizemos que ele está cometendo uma Violação das Máximas Conversacionais. Ao violar uma máxima, o locutor presume que o interlocutor compreende que suas palavras não devem ser consideradas literalmente e que ele é capaz de inferir a intenção implícita (LEÃO, 2013, p. 71).
\end{abstract}

Segundo Pinker (2008), a Violação das Máximas Conversacionais é o modo mais interessante e característico para perceber o Princípio da Cooperação e a ativação das implicaturas. Isso ocorre porque a violação de uma máxima é aparente, pois o falante pode querer tirar proveito de um enunciado e sabe que seu intérprete pode raciocinar e entender a implicatura relacionada aos propósitos imediatos da conversação.

O falante viola a Máxima da Quantidade quando fornece mais ou menos informações para um enunciado, como no exemplo:

- Exemplo 1: Ana: Como você está?

Paula: Ainda não enfartei.

No exemplo 1, é possível perceber a permanência da cooperação, pois infere-se que a pessoa está passando por problemas, mas, como ainda não sofreu nenhum mal sério de saúde, as coisas serão resolvidas. A máxima da relevância também é quebrada, pois a resposta não está adequada com a

${ }^{3}$ Grice (1975) ainda afirma que, quando a implicatura conversacional parte dessa situação (descumprimento espalhafatoso de uma máxima), há a exploração de uma máxima. 
pergunta realizada. Isso reforça a ideia de que, ao violar uma máxima, outras máximas também podem ser violadas.

A Violação da Máxima da Qualidade pode ser identificada no momento em que o falante diz aquilo em que acredita ser falso, como ocorre com as ironias, as metáforas, tautologias, exageros, eufemismos, brincadeiras afetivas etc.

- Exemplo 2 (ironia): A- Você está chorando?

B- Não, estou dando gargalhadas de alegria!

- Exemplo 3 (metáfora): Carlos é um anjo.

- Exemplo 4 (tautologia): Mãe é mãe.

- Exemplo 5 (exagero): Estou morrendo de fome.

- Exemplo 6 (eufemismo): Seu avô foi para o céu.

- Exemplo 7 (brincadeira afetiva): Você é um grande fanfarrão! Não vai me dar um abraço?

A violação de uma máxima ocorre, muitas vezes, para que não aconteça o conflito com outra máxima (GRICE, 1975, p. 49). Por exemplo, a Violação da Máxima da Quantidade pode aparecer com o intuito da Máxima da Qualidade seja preservada.

- Exemplo 8: A - Quantos filhos você tem?

B - Ah, João, tenho muitos filhos, entre 3 e 6.

No exemplo 8, o falante B é um pai desatento com a família ou tem filhos não legitimados, por isso, não tem certeza da quantidade de filhos que possui. Assim, prefere não abandonar a Máxima da Qualidade e lançar uma possibilidade, já que não teria evidência para dar uma resposta verdadeira e precisa.

A Violação da Máxima da Relevância pode ocorrer para preservar a Máxima da Qualidade "Faça com que sua contribuição seja verdadeira". O falante espera que o ouvinte possa fazer a relação entre os enunciados, interpretando o não-dito na sentença. Assim, o falante busca preservar a própria face:

- Exemplo 9: A- Você me ama?

B- Acho que vou para casa.

- Exemplo 10: A- Esse vestido ficou bem em mim?

B- Os seus sapatos estão bonitos. 
A Máxima de Modo indica que as pessoas não devem ser ambíguas e obscuras, e que devem evitar prolixidades e serem ordenadas. Por exemplo, a violação da máxima "Evite obscuridade" pode ocorrer para ocultar uma terceira pessoa ou objeto da conversa:

- Exemplo 11: Maria: Me sinto só.

Camila: Existe uma certa pessoa que poderia resolver essa solidão.

Ao violar uma ou mais Máximas Conversacionais, o falante quer transmitir determinados efeitos de sentido que sejam comunicativamente e sociavelmente aceitáveis. De acordo com Brown e Levinson (1987), o Princípio da Cooperação, além da transmissão de informações, também se aplica à manutenção das aparências, os falantes podem estar tentando se dar bem sem parecerem agressivos ou mal-humorados (PINKER, 2008). Por isso, as Implicaturas Conversacionais comandam vários tipos de sentidos não-literais, a exemplo do humor.

\section{O humor}

O humor faz parte da comunicação humana e tem funções que ultrapassam o simples fazer rir. Através do humor é possível ridicularizar, denunciar, quebrar paradigmas etc. Está presente em tantas áreas, que é um campo multi e interdisciplinar de estudos: existem abordagens de estudo históricas, antropológicas, comunicacional, semiológicas, sociológicas, psicológicas e linguísticas. Travaglia afirma que o humor pode ser analisado pelo viés da Linguística e que "todo humor resultante do desrespeito a regras conversacionais pode ser explicado, utilizando os princípios teóricos da análise da conversação" (TRAVAGLIA, 1990, p. 63).

A habilidade de apreciar e aproveitar o humor é universal e compartilhada pelas pessoas, independentemente de idade, cultura, sexo, época, posição social ou econômica. A universalidade do humor também é comprovada pelo fato de que muitas piadas ou situações irão ser consideradas engraçadas para a maior parte das pessoas. $O$ humor é parcialmente natural e parcialmente adquirido, 
assim como outros traços universais humanos como a fé, a língua, a moral (RASKIN, 1985).

Ainda sobre o caráter universal do humor, a partir da característica "não destacável" que as implicaturas possuem (LEVINSON, 2007), pode-se sugerir que uma mesma piada é engraçada para as pessoas mesmo que seja traduzida para outras línguas, pois o que importa no humor é o conteúdo semântico. Assim, a não "destacabilidade" (não destacáveis) das implicaturas reforça a ideia da universalidade do humor.

Raskin (1985), em sua teoria dos scripts ${ }^{4}$, ajusta o Princípio da Cooperação proposto por Grice com o intuito de explicar o humor. Considera que o Princípio da Cooperação rege uma comunicação bona-fide (de boa fé, confiável), na qual as informações são transmitidas de maneira séria e sincera, sem intenções ambíguas (o falante e o ouvinte estão comprometidos com a verdade). Para que o humor ocorra, precisa-se passar do modo bona-fide para o modo não-bona-fide de comunicação, no qual há Violações das Máximas Conversacionais com o objetivo de fazer o interlocutor rir através de inferências ou percepção de situações inusitadas.

Para explicar o humor, presente no gênero piada, como uma comunicação não bona-fide, Raskin (1985) propõe quatro tipos de situações que podem ser combinadas entre si:

a) O falante faz a piada sem intenção.

b) $O$ falante faz a piada intencionalmente.

c) O ouvinte não espera a piada.

d) O ouvinte espera a piada.

Em (a) o falante está engajado em uma comunicação bona-fide sem intenção de realizar enunciados ambíguos. Em (b), o falante explora a comunicação não bona-fide intencionalmente para criar um efeito especial de sentido que faça o ouvinte rir. Em (c), o ouvinte não espera a piada e interpreta o enunciado segundo os princípios da comunicação bona-fide. Quando essa

\footnotetext{
${ }^{4}$ Não se pretende, neste trabalho, aprofundar a teoria dos scripts, mas, sim, focalizar a necessidade do modo não bona-fide na construção do humor.
} 
interpretação falhar, o ouvinte precisa reanalisar o enunciado e entendê-lo no modo humor. Em (d), o ouvinte está de alguma forma "sintonizado" com a piada, e não tenta interpretar o enunciado como se fosse uma comunicação bona-fide, ao contrário, entende a piada como tal, com o mínimo ou sem esforço de compreensão.

Ao relacionar (a) e (c), pode ocorrer uma interpretação não humorística do enunciado. Tanto o falante como o ouvinte podem deixar de perceber a ambiguidade. Assim, a piada não ocorre e o não intencional e a ambuiguidade são suprimidos.

Ao relacionar (a) e (d), pode-se dizer que o falante está engajado em uma comunicação bona-fide, mas seu enunciado será interpretado como uma piada pelo ouvinte.

Ao relacionar (b) e (c), o ouvinte está engajado na comunicação bona-fide e, ao perceber que esse modo falha na interpretação de um enunciado ambíguo, precisa reanalisar o enunciado com base no modo não bona-fide e desvendar o efeito risível. $O$ autor sustenta a ideia que o humor é a interpretação mais provável, porque o contar piadas é mais sociavelmente aceito que as mentiras e as encenações (ou fingimentos).

Por fim, ao relacionar as condições (b) e (d), o falante e o ouvinte estão totalmente engajados em uma comunicação não bona-fide e, ao seguir essa categoria de comunicação, o ouvinte e o falante não estão preocupados apenas com humor, mas também um com o outro: estão de acordo que não encontrarão a verdade e a coerência, mas sim o inesperado e a "pegadinha". Pode-se afirmar que nesse tipo de situação a interação foi bem-sucedida, pois o humor causa prazer para quem o propõe e para quem o desvenda: o fazer rir é uma interação social privilegiada. Percebe-se que a cooperação presente nesse tipo de interação é um pouco diferente da proposta por Grice, pois falante e ouvinte cooperam entre si através de ambiguidades e não possuem expectativas com a verdade.

Conforme Raskin (1985), após a comunicação cooperativa bona-fide, o humor é a forma mais sociavelmente aceitável de comunicação. A partir dessa afirmação, pode-se deduzir que o sucesso da série The Big Bang Theory, que surgiu em 2007 e já está na nona temporada em 2015 (e previsão para novas 
temporadas), parte de seu caráter humorístico. Pode-se dizer que mesmo não tendo o perfil social e acadêmico dos personagens, as pessoas se identificam com a série devido à linguagem ${ }^{5}$, pois é comum as pessoas se comunicarem por meio dos jogos de linguagem, a exemplo do humor verbal ocasionado pela quebra das máximas conversacionais.

\section{Análise do corpus}

São analisados quatro recortes de diálogos ${ }^{6}$ extraídos da sitcom The Big Bang Theory. Como critério de seleção, foram escolhidas cenas que apresentam humor verbal em diálogos realizados pelos personagens, com 0 intuito de identificar de que maneira ocorre a Violação da Máximas da Conversação.

O seriado The Big Bang Theory é considerado uma sitcom, abreviatura de comedy situation, que é caracterizada da seguinte maneira:

Trata-se do ponto de vista humorístico, daquelas situações nas quais nos envolvemos diariamente que no momento nos parecem trágicas, mas vistas por alguém de fora, ou por nós mesmos após algum tempo do fato ocorrido, são engraçadas. (FURQUIM, 1999, p. 8).

Trata-se do cotidiano de quatro amigos, Sheldon, Howard, Rajesh e Leonard, que possuem as características típicas do grupo nerd: são muito inteligentes, gostam de histórias em quadrinhos (e de objetos baseados em histórias em quadrinhos), filmes e séries de ficção científica (por exemplo, o filme Star Wars), jogos eletrônicos, Comic-con, têm dificuldades de socialização (principalmente com mulheres) etc. Eles também têm uma forte amizade com a vizinha de Leonard e Sheldon, Penny ${ }^{7}$, que apesar de ter um estilo social diferente deles, inicia uma bela amizade com os garotos nerds. Além de

\footnotetext{
${ }^{5}$ Partindo da teoria da Identificação no Cinema, Galvão (2009) afirma que os espectadores se identificam com um programa (filmes, séries, novelas) pelas situações (trama) nas quais os personagens estão inseridos. Assim, existem fãs de The Big Bang Theory que, mesmo não sendo nerds, identificam-se com a série pelo modo como cada personagem reage e interage em diferentes situações cotidianas.

${ }^{6}$ Os diálogos analisados são transcrições das legendas disponibilizadas na série em DVD.

7 Nas temporadas mais recentes, outras personagens mulheres passam a fazer parte do círculo de relacionamentos dos quatro amigos.
} 
trabalharem juntos em uma universidade, esses amigos gostam de realizar reuniões para jogar e realizam jantares entre eles, nos quais sempre existem bastante conversas engraçadas para o espectador.

No episódio 2 da primeira temporada, os amigos Sheldon, Leonard, Rajesh e Howard estão reunidos e iniciam um rotineiro jantar. Rajesh, que tem origem indiana, pergunta se tem hashi, usado para comida japonesa:

\title{
Recorte 1:
}

\author{
Rajesh - Tem hashi? \\ Sheldon - Não precisa. Isso é comida Tailandesa. \\ Leonard - Aqui vamos nós! \\ Sheldon - A Tailândia usa garfos desde a segunda metade do século XIX. \\ O interessante é que eles não põem o garfo na boca. Eles usam para \\ colocar a comida na colher que vai à boca. \\ Leonard (dirige-se a Rajesh) - Pergunte sobre guardanapo. Eu te desafio!
}

Sheldon viola a Máxima da Quantidade e da Relação ao contribuir com uma informação mais informativa do que foi solicitada na conversa, ou seja, não precisava explicar sobre o uso do garfo na Tailândia e sim responder com "sim" ou "não". Com isso, o personagem também viola a Máxima de Modo "seja breve" ao ser prolixo", tentando manter a imagem do mais inteligente do grupo. Já Leonard, que conhece a fama de "grande explicador" que Sheldon possui, viola a Máxima de Modo ao ser obscuro com a expressão "Aqui vamos nós", indicando que Sheldon irá iniciar um comentário desnecessário.

O humor em (1) ocorre pela troca conversacional entre Sheldon e Leonard. Sheldon, geralmente, faz comentários que chateiam os colegas dele, principalmente por dar mais informação do que é exigida: ele quer reforçar seu perfil inteligente e adora demonstrar superioridade através das exposições de seus conhecimentos. Leonard sabe que a prolixidade de Sheldon pode irritar (e irrita) os outros amigos e, através de indiretas, tenta indicar que o amigo não inicie as amplas explanações. Sheldon não costuma inferir (ou finge não inferir) o sentido por trás das indiretas de Leonard, pois interpreta as sentenças pelo 
sentido convencional, e sempre prossegue sua fala. Assim, o espectador pode interpretar a resposta dada por Sheldon de duas maneiras: (a) ele não está sendo cooperativo com os objetivos imediatos da conversação ou (b) ele está sendo cooperativo e está querendo dizer outra coisa, como por exemplo que achou a pergunta feita por Rajesh boba e desnessária. O humor é reforçado na ironia final feita por Leonard: o espectador entende que Leonard não quer o início de uma nova explicação e sabe que Sheldon não desconfia que essa indireta foi um comentário negativo sobre sua prolixidade. Em suma, o humor em (1) ocorre pela resposta inusitada dada por Sheldon, na qual há a Violação da Máxima da Quantidade e da Relação.

É interessante salientar que situações conversacionais como em (1) ocorrem naturalmente no cotidiano das pessoas. Com isso, também surge um efeito de identificação com a situação através do uso da linguagem. Afinal, quem não tem um amigo que nunca entende indiretas e não consegue inferir o sentido não literal de algumas sentenças?

No episódio 6 da segunda temporada, o personagem Sheldon ganha a admiração de uma nova aluna da universidade. A intenção dela é fazer com que Sheldon aumente seus conhecimentos e contribua ainda mais com as teorias físicas. Para isso, a aluna passa uma temporada no apartamento de Sheldon e Leonard, investindo seu tempo ao dar motivações e conselhos para Sheldon. Os outros amigos ficam perplexos com o relacionamento do amigo com a aluna e a vizinha, Penny, fica curiosa em saber que pode acontecer um romance entre os dois. Em uma conversa sem a presença de Sheldon, Penny pergunta a Leonard, Rajesh (que não fala na presença de mulheres) e Howard:

Recorte 2:

Penny - Ouçam, eu sei que não é da minha conta, mas preciso perguntar qual é o negócio de Sheldon?

Leonard - Como assim "negócio"?

Penny - Qual o negócio dele? É homem, mulher, marionetes...?

Leonard - Operamos com a hipótese de que ele não tem um negócio.

Penny - Todo mundo tem um negócio! 
Howard - Não o Sheldon. Com o passar dos anos criamos várias teorias de como ele se reproduzia. Sou a favor da mitose.

Penny - Como assim?

Howard - Acredito que um dia Sheldon vai comer muita comida tailandesa e se dividir em dois Sheldons.

Leonard - Por outro lado, acho que Sheldon pode ser a larva de sua espécie e um dia vai surgir com as asas de mariposa e um exoesqueleto.

Penny - Ok. Obrigada pelos pesadelos.

Em (2) o humor é ocasionado pelas Violações das Máximas de Modo e de Qualidade. Penny viola a Máxima de Modo intencionalmente ao fazer um questionamento obscuro e ambíguo sobre Sheldon através do sentido não convencional da palavra negócio. Leonard parece não entender o significado literal da sentença e pede uma explicação mais clara. Então, Penny esclarece o sentido "não-literal" de negócio: não está relacionado com questões empresariais e com a opção sexual de Sheldon. Leonard entende a implicatura que há por trás de "homem, mulher, marionete..." e passa a cooperar melhor na conversa, violando a Máxima de Modo ao ser obscuro (continua a usar o termo negócio), e a Máxima da Qualidade ao dizer "Acreditamos que ele não tem um negócio", e isso é algo para o qual ele não tem provas. Penny, por sua vez, não acredita que Sheldon não tenha uma preferência sexual e afirma que "Todo mundo tem um negócio", continuando a violar a Máxima de Modo e a Máxima da Qualidade.

A partir disso, pode-se perceber a ativação do modo não bona-fide de comunicação característico das piadas: não haverá verdades e sentenças coerentes e os ouvintes sabem disso. Howard inicia as suposições sobre "os negócios" de Sheldon violando a Máxima da Qualidade, afinal, nenhum ser humano pode se reproduzir por mitose, muito menos após a ingestão de comida tailandesa. Leonard continua a violar a Máxima da Qualidade ao comparar a reprodução de Sheldon à reprodução das mariposas. Penny percebe que sua curiosidade iniciou uma conversa com suposições esquisitas e tenta pôr fim ao dizer "Ok. Obrigada pelos pesadelos".

As indiretas realizadas em (2) e as suposições inadequadas sobre a reprodução de Sheldon indicam que os relacionamentos amorosos de Sheldon 
são improváveis e até tabu. Penny prefere utilizar o termo "negócio" para disfarçar o assunto, com o intuito de não constranger os rapazes e também não parecer mais curiosa do que está. Quando Penny tenta esclarecer o termo "negócio", surge o humor, pois, além de fornecer pistas para a implicatura esperadas (homem, mulher), também dá uma pista inesperada (marionetes). Com isso, Penny quer dizer que quer saber se Sheldon se relaciona amorosamente com alguém e qual sua opção sexual, por mais exótica que seja.

No episódio 4 da terceira temporada, Rajesh perdeu o vínculo na universidade e está sendo ameaçado com a deportação para a Índia, seu país de origem. Essa deportação só não ocorrerá se conseguir um novo emprego. Em um rotineiro jantar, os quatro amigos estão reunidos na sala e Sheldon surge com a notícia sobre um emprego para Rajesh:

\section{Recorte 3:}

Sheldon - Consegui uma verba extra da direção do departamento e Raj pode trabalhar para mim.

Rajesh - Quer que eu trabalhe com você?

Sheldon - Para mim. Precisa ouvir com mais atenção no trabalho.

Rajesh - Por favor, não me entenda mal. Mas, prefiro nadar pelado no rio Gangee com um corte feito por papel no mamilo e ter uma morte lenta por infecção viral a trabalhar com você.

Sheldon - Para mim.

Sheldon inicia a conversa adotando o modo bona-fide de comunicação: sua sentença possui o significado literal apresentado. Rajesh, empolgado com a notícia, repete o que acabou de ouvir como se não estivesse acreditando na proposta do amigo. Sheldon, então, quebra a expectativa da resposta, pois no lugar de confirmar explicitamente sua proposta, preocupa-se em destacar o significado do "para mim". Além disso, Sheldon lança a primeira crítica a Rajesh: "Precisa ouvir com mais atenção no trabalho". O personagem Rajesh viola a Máxima da Qualidade e Quantidade, pois no lugar de dizer simplesmente "não" à proposta de trabalho feita por Sheldon, dá uma resposta que acredita ser falsa e 
que é desnecessariamente informativa: certamente ele não tem a pretensão de morrer de infecção ao nadar com um ferimento no rio Gangee.

O humor gerado por Sheldon parte de sua aparente permanência no modo bona-fide de comunicação: ele não está interessado apenas na resposta de Rajesh, mas que a interpretação literal de sua expressão seja realizada: trabalhar "para ele" e não "com ele". Com isso, mais uma vez, Sheldon pretende manter sua aparente superioridade: não precisa de um companheiro de trabalho e sim de um ajudante, que não interfira nas suas "atribuições intelectuais superiores". Rajesh entende a intenção de Sheldon e sente-se magoado. Por isso, viola as Máximas da Qualidade e Quantidade intencionalmente com o mesmo objetivo de manter as aparências: prefere ser deportado que contribuir com a elevação do ego de Sheldon.

O personagem Rajesh transfere sua comunicação para o modo não bonafide e o espectador interpreta sua resposta como tal, surgindo o humor. Porém, o humor tem ainda prosseguimento quando Sheldon permanece no modo bonafide, e não infere o que o amigo quis dizer, insistindo que Rajesh trabalhará para ele (estrutura linguística). Essa troca de modos de comunicação cria um efeito de humor bastante interessante para o espectador da série, que precisa ficar atento ao que é dito para conseguir interpretar os enunciados inesperados.

Ainda no episódio 4 da terceira temporada, em outro momento de interação, os quatro amigos cientistas estão reunidos na sala de jantar, juntamente com a vizinha Penny. No contexto, conversam sobre o dia de Ação de Graças:

Recorte 4:

Penny - Isso me lembrou de que sempre que vou a Nebraska no Ação de Graças. Mas, este ano cancelaram devido ao julgamento do meu irmão.

Leonard - Ele vai ser julgado por quê?

Penny - Foi um grande mal-entendido... Sabe, ia gostar do meu irmão. Ele é tipo um químico. 
Percebe-se que Leonard e Penny, inicialmente estão vinculados no modo bona-fide de comunicação: Penny relembra que volta a sua cidade de origem no dia de Ação de Graças, mas que houve um cancelamento da reunião anual com a família por causa do julgamento do irmão. Leonard coopera com a conversa e logo pergunta sobre o motivo de tal julgamento. Penny então, viola a Máxima da Quantidade "não diga nada menos do que a conversa exige" ao dizer apenas que "Foi um grande mal-entendido". Após isso, viola a Máxima da Qualidade "Não diga o que você acha ser falso" ao afirmar que o irmão "é tipo um químico".

A função da Violação da Máxima da Qualidade ocorre intencionalmente para que o ouvinte implique que ela não quer falar sobre o assunto, por isso, a personagem tenta mudar um pouco o tema da conversa. Ao mudar o tema, Penny viola a Máxima da Qualidade e é onde surge o humor: na verdade, seu irmão não é um químico cientista, semelhante ao grupo de amigos presentes na sala, e sim um "químico" devido ao conhecimento químico que tem das drogas pelo vício que possui.

Através dos fragmentos selecionados para a presente análise, fica claro que o humor verbal é explorado nas interações entre os personagens através das violações das máximas conversacionais. $O$ efeito de humor permanece mesmo nas traduções dos fragmentos, reiterando o caráter universal do humor através da não destacabilidade das implicaturas.

\section{Considerações finais}

Através da análise de fragmentos conversacionais extraídos da série The Big Bang Theory, pode-se verificar que os personagens estão sempre realizando jogos com a linguagem através de um discurso de indiretas e transmitindo conteúdos implícitos. Assim, a partir dos trechos analisados, pode-se dizer que no processo de construção do humor em comédias de situação, sitcoms, a Violação das Máximas Conversacionais é algo recorrente e tem o objetivo primordial de produzir o humor verbal.

Há indícios de que as pessoas se identificam com o seriado, mesmo que, por vezes, não entendam as temáticas das conversas presentes no cotidiano do grupo nerd. Nas situações conversacionais (trechos analisados), os personagens 
violam as máximas para que o humor seja produzido. Assim, as pessoas (espectadores) se identificam com as situações verbais da sitcom porque violam as máximas e propõem implicaturas comumente. Com o intuito de reconhecer o humor nas Violações das Máximas Conversacionais, acredita-se que o espectador realiza o processo de transição do modo bona-fide para o modo não bona-fide.

Compreende-se também que a Violação das Máximas Conversacionais tem a função de resguardar as aparências (BROWN; LEVINSON, 1987; PINKER, 2008) dos personagens: alguns procuram ser cuidadosos com o que dizem, apresentando um caráter mais modesto, já outro pode ter o objetivo de aparentar superioridade intelectual sobre seus colegas. As tentativas de aparentar ser superior do personagem Sheldon também é um recurso que causa humor.

Ademais, os interlocutores reais, ou espectadores, reconhecem o humor mesmo na tradução literal das interações verbais dos personagens. Esse fator corrobora a não destacabilidade (não destacáveis) das implicaturas: a implicatura ocorre independentemente da expressão linguística. Assim, reforça-se o caráter universal do humor proposto por Raskin (1985). Percebe-se ainda que a cooperação entre os interlocutores continua, pois, a violação das máximas são intencionais.

A importância de analisar o humor sob a perspectiva da Pragmática Conversacional pode ser a chave para compreender os implícitos conversacionais e como a violação das máximas pode revelar as características de cada personagem da série. Assim, o caráter universal do humor e sua compreensão em diferentes tipos de cultura é um exemplo bastante convincente de que existem muitos significados nas entrelinhas do discurso e que as implicaturas são amplamente ativadas e estão presentes nas conversações, sejam elas fictícias ou naturalísticas.

\section{ANALYSIS OF IMPLICATURES AND THE VIOLATION OF CONVERSATIONAL MAXIMS IN THE BIG BANG THEORY SITCOM}

ABSTRACT: The present paper aims at analyzing excerpts of dialogues from the TV series The Big Bang Theory under the perspective of conversational pragmatics (GRICE, 1975). More specifically, we analyze how verbal humor is caused by the violation of conversational maxims, by 
implications and by the relationship of the interlocutors in the change of the bona-fide to the non bona-fide script of communication (RASKIN, 1985). It could be verified that the intention of the violations of the conversational maxims is to cause humor, and that the non-detachability of the implicatures allows the perception of humor even in the literal translation of the analyzed corpus, corroborating the universal characteristic of humor.

KEYWORDS: Conversational Pragmatics. Conversational Maxims. Implicatures. Humor.

\section{Referências}

BROWN, P; LEVINSON, S. Politeness. Cambridge: Cambridge University Press, 1987.

FURQUIN, F. Sitcom - Definição e história. Porto Alegre: FCF, 1999.

GALVÃO, D. P. Os nerds ganham poder e invadem a TV. Intr@aciência, Uniesp, p. 34-41, 2009.

GRICE, H. P. Logic and Conversation. In: COLE, P; MORGAN, J. (ed.). Pragmatics (Syntax and Semantics), vol. 9, Nova York: Academic Press, 1975.

LEÃO, L. B. C. Implicaturas e a violação das máximas conversacionais: uma análise do humor em tirinhas. Work. Pap. Linguíst. Florianópolis, 2013.

LEVINSON, S. C. Pragmática. Tradução de Luís Carlos Borges, Aníbal Mari. São Paulo: Martins Fontes, 2007.

OLIVEIRA, R. P; BASSO, R. M. Arquitetura da Conversação: teoria das implicaturas. São Paulo: Parábola Editorial, 2014.

PINKER, S. Do que é feito o pensamento: a língua como janela para a natureza humana. São Paulo: Companhia das Letras, 2008. 561 p.

RASKIN, V. Semantic Mechanisms of Humor. Dordrecht: D. Reidel, 1985.

THE Big Bang Theory. Direção: Chuck Lorre; Bill Prady. Produção: Chuck Lorre; Bill Prady; Lee Aronsohn. Intérpretes: Johnny Galecki; Jim Parsons; Kaley Cuoco; Simon Helberg; Kunal Nayyar. Los Angeles: Warner Bros, c2008. $1^{\text {a }}$ temporada completa. 3 DVDs (356MIN), Color. Produzido por Warner Bros.

THE Big Bang Theory. Direção: Chuck Lorre; Bill Prady. Produção: Chuck Lorre; Bill Prady. Intérpretes: Johnny Galecki; Jim Parsons; Kaley Cuoco; Simon Helberg; Kunal Nayyar. Los Angeles: Warner Bros, c2009. 2 $2^{\mathrm{a}}$ temporada completa. 4 DVDs (478MIN), Color. Produzido por Warner Bros.

THE Big Bang Theory. Direção: Chuck Lorre; Bill Prady. Produção: Chuck Lorre; Bill Prady. Intérpretes: Johnny Galecki; Jim Parsons; Kaley Cuoco; Simon 
Helberg; Kunal Nayyar. Los Angeles: Warner Bros, c2010. 3 temporada completa. 3 DVDs (472MIN), Color. Produzido por Warner Bros.

TRAVAGLIA, L. C. Uma introdução ao estudo do humor pela linguística. Delta, São Paulo/SP: Pontifícia Universidade Católica, p.55-82, 1990.

Data de Submissão: 30/08/2017

Data de Aprovação: 27/12/2017 